\title{
The Th1-Th2 model—what relevance to inflammatory arthritis?
}

Just over a decade ago Mosmann and colleagues reported that murine $\mathrm{T}$ helper ( $\mathrm{Th}$ ) cell clones could be distinguished by distinct cytokine secretion patterns. ${ }^{1}$ Since then the concept of Th1 and Th2 subsets has become increasingly popular and the Th1-Th2 model represents one of the most important developments in our understanding of immunological processes in health and disease.

The model encompasses two concepts derived from in vitro observations of longlived murine $\mathrm{T}$ cell clones: (1) $\mathrm{CD} 4^{+} \mathrm{T}$ cells may be classified into $\mathrm{Th} 1$ and $\mathrm{Th} 2$ subsets, based on the production of two functionally distinct profiles of cytokines. Th1 cells produce interferon $\gamma$ (IFN $\gamma$ ), interleukin 2 (IL2), and tumour necrosis factor $\beta$ (TNF $\beta$ ), and in broad terms induce cell mediated immunity. Th2 cells secrete interleukins 4 (IL4), 5 (IL5), 6 (IL6), 10 (IL10), and 13 (IL13) and induce humoral and parasitic immunity. (2) Factors that stimulate the actions of one subset reciprocally inhibit the other subset, leading to a state of mutual antagonism. Thus IFN $\gamma$ and interleukin 12 (IL12) stimulate Th1 cells and inhibit Th2 cells whereas IL4 stimulates Th2 cells and inhibits Th1 cells.

More recently the original clear cut concept that the Th1-Th2 split may be applied to individual Th cells has evolved. Early observations from T cell clones demonstrated that single Th cells secrete either a pure Th1 or Th2 profile of cytokines. However, freshly isolated Th cells from antigen stimulated animals express a range of Th1 and Th2 cytokines (mRNA and protein) in a random distribution. This pattern has not been found to develop in individual cells in culture into the exclusive Th1 or Th2 pattern observed in clonal cells. Instead, the Th1 or Th2 characteristics of an in vivo immune response seems to be determined by a net shift in the secretion profile of a population of Th cells towards a Th1 or Th2-like response, in which each individual cell retains a mixed picture to a greater or lesser extent. ${ }^{2}$

There is no doubt that the distinct Th1 and Th2 cytokine profiles observed in vitro have critical biological outcomes in some in vivo situations, most notably infections. For example Leishmania major infection in mice results in a protective response in some strains (C57B6) characterised by a Th1 cytokine pattern, or a susceptible response in other strains $(\mathrm{BALB} / \mathrm{c})$ characterised by a Th2 cytokine pattern. ${ }^{3}$ Treatment with neutralising antibodies to IL4 or IFN $\gamma$ changes survival, demonstrating a critical role in the Th1-Th2 balance in determining the outcome to infection. This is also seen in humans where the sequelae of infection with Mycobacterium leprae seem to be dependent on the Th1-Th2 split, as the dominant response in tuberculoid disease is of the Th1 type and the dominant response in lepromatous disease is of the Th2 type. ${ }^{4}$

In humans the interpretation of the contribution of $\mathrm{Th}$ cells and their cytokines to the pathogenesis of autoimmune disease is complex and problematic. Firstly, Th secretory responses in humans are not identical to the mouse; IL2, IL6, IL10, and IL13 are produced by both Th1 and Th2 cells in humans, but only by Th1 (IL2) or Th2 (IL6, 10, and 13) cells in the mouse. This undermines the wisdom of applying conclusions concerning the Th1-Th2 split in animal models of disease directly to humans.
Secondly, Th cytokines are not exclusively secreted by Th cells. Mast cells and basophils, for example, produce IL4 whereas natural killer (NK) cells and murine macrophages produce IFN $\gamma$. B cells and monocytes produce IL10 and macrophages, fibroblasts, chondrocytes and endothelial cells produce IL6. CD8 T cells also contribute to the same cytokine environment, for example in the rat the expression of IL4, 5, 10 and IFN $\gamma$ mRNA is twofold to fivefold higher in stimulated splenic CD8 T cells compared with CD4 (Th) cells. ${ }^{5}$ This introduces the confusion that while Th1 and Th2 cells are defined by the pattern of cytokines that they secrete the same pattern of cytokines at an inflammatory site does not necessarily imply an involvement of Th1 or Th2 cells. To date no distinguishing Th1 or Th2 surface markers have been described to solve this problem.

A huge volume of work has been devoted to categorising the pathogenesis of inflammatory arthritis in terms of the Th1-Th2 split, driven quite reasonably by the near universal $\mathrm{T}$ cell dependence of animal models and a strong body of evidence supporting a role for $\mathrm{T}$ cells in human arthritis. Evidence from a number of experimental autoimmune diseases has led to the broad conclusion that the function of Th1 cells is pro-inflammatory and that of Th2 cells is anti-inflammatory. ${ }^{6}$ In some animal models of arthritis this paradigm seems to hold true. For example in pristane induced arthritis (PIA) in mice arthritogenic T cells secrete IFN $\gamma$ and IL2 whereas T cells from protected animals secrete IL4 and IL5, suggesting that the response in susceptible animals is of the Th1 type and in protected animals of the Th2 type. ${ }^{7}$ Similarly in murine aggrecan induced arthritis the cytokine profile from arthritogenic $T$ cell hybridomas is of the Th1 type, ${ }^{8}$ and in rat streptococcal cell wall induced arthritis (SCWA) IL4 has an anti-inflammatory effect in ameliorating the chronic phase of arthritis. ${ }^{9}$

The picture becomes increasingly complex in collagen induced arthritis (CIA), probably the most widely studied model of all. In some circumstances CIA seems to be a Th1 driven disease, as seen in PIA, SCWA, and aggrecan arthritis. Thus CIA induced with complete Freund's adjuvant (CIA/CFA) is exacerbated after treatment with low concentration IFN $\gamma$ injected intramuscularly ${ }^{10}$ or locally into the footpad, ${ }^{11}$ and when induced with incomplete Freund's adjuvant (CIA/IFA) is exacerbated by IL12 (an enhancer of Th1 responses). ${ }^{12}$ Similarly a Th1 process is suggested by the report that selective inhibition of Th1 responses ${ }^{13}$ or treatment with either anti-IFN $\gamma,{ }^{14}$ IL4 or IL13 is protective. ${ }^{15}$ In contrast, however, IL12 treatment has been reported to ameliorate $\mathrm{CIA} / \mathrm{CFA}^{16}$ as has treatment with high concentrations of IFN $\gamma$ injected systemically. ${ }^{17}$ In keeping with these observations that Th1 responses might have an anti-inflammatory role in some circumstances, treatment with anti-IFN $\gamma$ is also reported to increase disease severity in CIA/CFA ${ }^{14} 18$ and in IFN $\gamma$ knock out mice CIA/CFA is more severe ${ }^{19}$ Furthermore in two lines of Biozzi mice analysis of Th cytokine responses indicates that the Th1 phenotype characterises resistance and the Th2 phenotype characterises susceptibility to CIA/CFA. ${ }^{20}$ Finally Doncarli et al report that collagen specific Th cells change in phenotype from a Th1 to a Th2 pattern during the induction of CIA/CFA. ${ }^{21}$ These observations in CIA undermine the general concept that 
Th1 responses are arthritogenic and Th2 responses protective - and they are not unique to this model. In chronic murine arthritis intra-articular anti-IL4 is protective whereas IL2 and IL4 are synergistic in the potentiation of antigen induced arthritis flare. ${ }^{22}$ Lastly in the mercuric chloride model of autoimmunity Brown Norway rats develop a severe inflammatory arthritis that is $T$ cell dependent and arises in the context of a Th2 dominated immune response. ${ }^{23}$

The conclusion from these extensive studies in animals is that there is no stereotyped role for the Th1-Th2 model in the pathogenesis of inflammatory arthritis, with both Th1 and Th2 cytokines apparently acting in pro or antiinflammatory capacities in different circumstances. In humans experimental techniques to probe mechanisms of disease are constrained; none the less attempts to interpret arthritogenic mechanisms in terms of the Th1-Th2 model have been made.

In rheumatoid arthritis (RA) synovial tissue the cytokine profile reflects the large volume of activated macrophages, making an interpretation of the role of Th subsets on the basis of particular cytokines virtually impossible. Both IFN $\gamma$ and IL2 are present in small quantities, and IL4 is seemingly absent. However, the relevance of this observation to the Th1-Th2 model is unclear as IL2 is not restricted to either subset in humans, and IFN $\gamma$ may also be secreted by CD8 and NK cells, and macrophages in mice. Chomarat et $a l^{24}$ have isolated synovial fluid $\alpha / \beta$ and $\gamma / \delta \mathrm{T}$ cell clones from several RA patients and found that most of the clones produce IFN $\gamma$, but a substantial proportion also produce IL4. The relative IFN $\gamma / \mathrm{IL} 4$ production by these clones indicates a Th1-like bias in the majority, however the secretion profile is clearly of the Th2 type in a minority. The apparent Th1 bias in the rheumatoid joint has led to the broad conclusion that RA is a Th1 mediated disease. ${ }^{6}$ In contrast a number of trials have reported the effect of IFN $\gamma$ treatment in RA, based on the observation that IFN $\gamma$ may antagonise the actions of the macrophage cytokines $\mathrm{TNF} \alpha$ and IL1. Interestingly the data show either a weak protective effect or no difference compared with placebo, ${ }^{25}$ rather than an exacerbation in disease activity as might be predicted if RA were a Th1 driven disease.

In reactive arthritis ( $\operatorname{ReA}$ ) and Lyme arthritis (LyA) antigen specific stimulation of synovial fluid mononuclear cells (SFMC) reveals IFN $\gamma$, IL10, and TNF $\alpha$ secretion and little, if any, IL4. ${ }^{26}{ }^{27}$ The production of IFN $\gamma$ and the demonstration that antigen induced SFMC proliferation is enhanced by IL12, and abolished by IL10, suggests a Th1like response to antigen in these two diseases.

An anti-inflammatory role for the Th2 cytokine IL4 has been demonstrated when added to RA synovium in vitro. ${ }^{28}$ However, the detection of this cytokine in vanishingly small concentrations in $\mathrm{RA}, \mathrm{ReA}$, and $\mathrm{LyA}^{26}{ }^{27}$ raises doubt as to whether it has a significant role in the control of joint inflammation. In contrast, in RA, ReA, and LyA joints IL10 is present in significantly greater concentrations than IL4 and seems to have a greater anti-inflammatory effect. For example IL10 has a pronounced inhibitory effect on TNF $\alpha$ secretion in RA, ReA, and LyA synovial cultures, whereas IL4 (and IL13 in RA) has not been found to have a significant effect. ${ }^{262729}$ The demonstration of a significant anti-inflammatory role for IL10 in vivo cannot be taken as evidence for Th2 involvement. IL10 is secreted by Th cells and monocytes in synovial membranes, and has recently been reported to be secreted in high concentration by a separate subset of antigen specific T "regulatory" cells, so called Tr 1 cells. ${ }^{30}$ Until the principal cellular source of IL10 in the inflamed joint is known, an anti-inflammatory role, if any, for Th2 cells through IL10 production remains unproved.

In conclusion the revolution in our understanding of $\mathrm{T}$ cell biology on the basis of the Th1-Th2 model does not provide a dogmatic interpretation of the pathogenesis of inflammatory arthritis, either in animals or in humans. Some of the data support the general concept that inflammatory processes in the joint may be promoted by Th1 cytokines, but the evidence that Th2 cells play a critical part in counteracting this is weak. Furthermore the realisation that so called Th2 cytokines may play a proinflammatory part in some circumstances cannot be overlooked and is an example of an important principle: joint inflammation may result from a multitude of different mechanisms. Attractive as it may be, the Th1-Th2 model does not seem to be a basic pathogenic template for inflammatory arthritis; it may therefore be unwise to use it as a foundation upon which to devise new therapeutic strategies.

PATRICK D W KIELY Department of Rheumatology, St George's Healthcare NHS Trust, Blackshaw Road, London SW17 0QT

1 Mosmann TR, Cherwinski H, Bond MW, Giedlin MA, Coffman RL. Two types of murine helper $T$ cell clone. I. Definition according to profiles of lymphokine activities and secreted proteins. J Immunol 1986;136:2348-57. 2 Kelso A. Th1 and Th2 subsets: paradigms lost? Immunol Today 1995; 16:374-9.

3 Heinzel FP, Sadick MD, Holaday BJ, Coffman RL, Locksley RM. Reciprocal expression of interferon gamma or IL4 during the resolution or progression of murine leishmaniasis. Evidence for expansion of distinct helper T cell subsets. J Exp Med 1989;169:59-72.

4 Salgame P, Abrams JS, Clayberger C, Goldstein H, Convit J, Modlin RL, et al. Differing lymphokine profiles of functional subsets of human CD4 and CD8 T cell clones. Science 1991;254:279-82.

5 Noble A, Macary PA, Kemeny DM. IFN-g and IL-4 regulate the growth and differentiation of CD8+ $\mathrm{T}$ cells into subpopulations with distinct and differentiation of CD8+ T cells into subp
cytokine profiles. J Immunol 1995;155:2928-37.

6 Trembleau S, Germann T, Gately MK, Adorini L. The role of IL-12 in the induction of organ-specific autoimmune diseases. Immunol Today $1995 ; 16: 383-6$.

7 Elson CJ, Barker RN, Thompson SJ, Williams NA. Immunologically ignorant autoreactive $\mathrm{T}$ cells, epitope spreading and repertoire limitation. Immunol Today 1995;16:71-6.

8 Buzas EI, Brennan FR, Mikecz K, Garzo M, Negroiu G, Hollo K, et al. A proteoglycan (aggrecan)-specific $\mathrm{T}$ cell hybridoma induces arthritis in BALB/c mice. J Immunol 1995;155:2679-87.

9 Allen JB, Wong HL, Costa GL, Bienkowski MJ, Wahl SM. Suppression of monocyte function and differential regulation of IL-1 and IL-1ra by IL-4 contribute to resolution of experimental arthritis. J Immunol 1993;151: 4344-51.

10 Cooper SM, Sriram S, Ranges GE. Suppression of murine collagen-induced arthritis with monoclonal anti-Ia antibodies and augmentation with IFNg. J Immunol 1988;141:1958-62.

11 Mauritz MJ, Holmdahl R, Jonsson R, van der Meide PH, Scheynius A, Klareskog L. Treatment with gamma-interferon triggers the onset of collaKlareskog L. Treatment with gamma-interferon triggers the
gen arthritis in mice. Arthritis Rheum 1988;31:1297-304.

12 Germann T, Szeliga J, Hess H, Storkel S, Podlaski FJ, Gately MK, et al. Administration of interleukin 12 in combination with type II collagen induces severe arthritis in DBA/1 mice. Proc Natl Acad Sci USA 1995;92: 4823-7.

13 Hughes C, Wolos JA, Giannini EH, Hirsch R. Induction of T helper cell hyporesponsiveness in an experimental model of autoimmunity by using nonmitogenic anti-CD3 monoclonal antibody. J Immunol 1994;153:331925.

14 Boissier M-C, Chiocchia G, Bessis N, Hajnal J, Garotta G, Nicoletti F, et al. Biphasic effect of interferon-g in murine collagen-induced arthritis. Eur J Immunol 1995;25:1184-90.

15 Bessis N, Boissier M-C, Ferrara P, Blankenstein T, Fradelizi S, Fournier C. Attenuation of collagen-induced arthritis in mice by treatment with vector cells engineered to secrete interleukin-13. Eur J Immunol 1996;26:2399403 .

16 Hess H, Gately MK, Rude E, Schmitt E, Szeliga J, Germann T. High doses of interleukin-12 inhibit the development of joint disease in DBA $/ 1$ mice immunized with type II collagen in complete Freund's adjuvant. Eur J Immunol 1996;26:187-91.

17 Nakajima H, Takamori H, Hiyama Y, Tsukada W. The effect of treatment with interferon-gamma on type II collagen-induced arthritis. Clin Exp Immunol 1990;81:441-5

18 Williams RO, Williams DG, Feldmann M, Maini RN. Increased limb involvement in murine collagen-induced arthritis following treatment with anti-interferon-gamma. Clin Exp Immunol 1993;92:323-7.

19 Manoury-Schwartz B, Chiocchia G, Bessis N, Abehsira-Amar O, Batteux F, Muller S, et al. High susceptibility to collagen-induced arthritis in mice lacking IFN-gamma receptors. J Immunol 1997;158:5501-6.

20 De Franco M, Gille- Perramant M-F, Mevel J-C, Couderc J. T helper subset involvement in two high antibody responder lines of mice (Biozzi mice): $\mathrm{HI}$ (susceptible) and HII (resistant) to collagen-induced arthritis. Eur J Immunol 1995;25:132-6.

21 Doncarli A, Stasiuk LM, Fournier C, Abehsira-Amar O. Conversion in vivo from an early dominant $\mathrm{Th} 0 / \mathrm{Th} 1$ response to a Th2 phenotype during the development of collagen-induced arthritis. Eur J Immunol 1997;27: 1451-8. 
22 Jacobs MJM, van den Hoek AEM, van Lent PLEM, van de Loo FAJ, van de Putte LBA. Role of IL-2 and IL-4 in exacerbations of murine antigen-induced arthritis. Immunology 1994;83:390-6.

23 Kiely PDW, Thiru S, Oliveira DBG. Inflammatory polyarthritis induced by mercuric chloride in the Brown Norway rat. Lab Invest 1995; 73:284-93.

24 Chomarat P, Kjeldsen-Kragh J, Natvig JB, Miossec P. Different cytokine production profiles of $\mathrm{gd} \mathrm{T}$ cell clones: relation to inflammatory arhtritis. Eur J Immunol 1994;24:2087-91.

25 Veys EM, Menkes C-J, Emery P. A randomized double-blind study comparing twenty four-week treatment with recombinant interferon-g versus placebo in the treatment of rheumatoid arthritis. Arthritis Rheum 1997;40: 62-8.

26 Yin Z, Braun J, Neure L, Wu P, Eggens U, Krause A, et al. T cell cytokine pattern in the joints of patients with Lyme arthritis and its regulation by cytokines and anticytokines. Arthritis Rheum 1997;40:69-79.
27 Yin Z, Braun J, Neure L, Wu P, Liu L, Eggens U, Sieper J. Crucial role of interleukin 10/interleukin 12 balance in the regulation of the type $2 \mathrm{~T}$ helper cytokine response in reactive arthritis. Arthritis Rheum 1997;40: 1788-97.

28 Miossec P, Briolay J, Dechanet J, Wijdenes J, Martinez-Valdez H, Banchereau J. Inhibition of the production of proinflammatory cytokines and immunoglobulins by interleukin- 4 in an ex vivo model of rheumatoid synovitis. Arthritis Rheum 1992;35:874-83.

29 Hart PH, Ahern MJ, Smith MD, Finlay-Jones JJ. Regulatory effects of IL-13 on synovial fluid macrophages and blood monocytes from patients with inflammatory arthritis. Clin Exp Immunol 1995;99:331-7.

30 Groux H, O'Garra A, Bigler M, Rouleau M, Antonenko S, de Vries JE, et al. A CD4+ T-cell subset inhibits antigen-specific T-cell responses and prevents colitis. Nature 1997;389:737-42. 